\title{
STRATEGIES OF DIGITAL KNOWLEDGE'S REPRESENTATION: FROM DE- MORPHOGENESIS AT MSH-BIM. OPTICAL, THEATRICAL ILLUSION AND PERSPECTIVE IN THE NEAPOLITAN SCHOOL'S ARCHITECTURE DRAWING
}

\author{
A. De Masi \\ ABC, Dept. of Architecture, Built Environment and Construction Engineering, Milan Polytechnic, School of Design, Via Ponzio \\ 31,20133 Milan - alessandro.demasi@polimi.it - alessandro.demasi@unina.it
}

Commission VI, WG VI/4

\begin{abstract}
KEY WORDS: Architectural-scenographic construction, Theatrical scenic illusionism, DSH (De-Morphogenesis, Semantic, Hypermedia Systems) - BIM (Building Information Modelling), Digital Platform for the Knowledge's Representation, Morphology of the Form, De-Morphogenesis of the Architecture, Semantic Values of the Architecture by On-Morphogenesis, Hypermedia Systems and Cloud Computing Platforms.
\end{abstract}

\begin{abstract}
:
The study illustrates the architectural-scenographic construction and drawing techniques related to theatrical scenic illusionism of the seventeenth and eighteenth centuries in relationship with some Neapolitan monumental buildings. In addition the develop of methodologies of intervention DSH (De-Morphogenesis, Semantic, Hypermedia Systems) - BIM (Building Information Modelling) in the historical reality as new concept of "Smart Heritage". Therefore, the objective of the research is the construction of the visual model of documentation defined as "Digital Platform for the Knowledge's Representation" of classification and comparison data. The methodological operations will be based on the "Morphology of the Form", the "De-Morphogenesis of the Architecture", "Semantic Values of the Architecture by On-Morphogenesis and "Hypermedia Systems and Cloud Computing Platforms". The research highlighted for architectural elements: 1) Lexicon, Syntax and Semantics. 2) Ripercussion on representative categories. 3) Solutions adopted to check the conservation condition. 4) manipulation based on dimensional parameters. 5) 3D parametric digital models with appropriate stylistic features in the same way as reverse engineering solutions.
\end{abstract}

\section{INTRODUCTION}

The research goal is related to a demand for digital documentation, communication and tools learning of architectural drawing and Cultural Heritage $(\mathrm{CH})$; this in order to support the phase of knowledge's development according to the UNESCO WHC (France), ICOMOS (France), ICOMOS (Australia) and ICOMOS-ICIP (USA) directives. All this is debate's part on the relationship between architecture information and representation tool in which the architectural drawing's role expands in the urban modern voids with innovative solutions related to $\mathrm{CH}$ for renews the cultural perception of the city's identity. In particular the Burra Charter includes "interpretative measures/readings" intended as "range of values for different individuals or groups" (ICOMOS, 2013). This because the urban landscape is defined as: "urban area understood as the result of a historic layering of cultural and natural values and attributes...." (UNESCO, 2011). The interpretative urban voids system's values is intended as a central function in relation to the capabilities of: 1) Represent the "ordering elements" of urban fragments, identifying digital, functional, dimensional and integration mediators the genius loci. 2) Design a "recognizable and harmonious integration", as advocated by Frank Lloyd Wright (1867-1959), in which spatiality is defined by thresholds and representative-design itinerary. 3) Identify, through the iteration of hypermedia systems, "areas of experimentation and of integration" where pre-existing elements are seed and traces, as advocated for by Tadao Ando. 4) Create "new scenographic contexts", generated by visual reflections and decomposition of light-color in relation to historical-cultural values, to activate the matter. Therefore, the research, through visual architectural analysis based on the "De-morphogenesis and On-Morphogenesis of the
Architecture", highlights the graphic models of the Neapolitan School's Architecture Drawing (Domenico Fontana 15431607, Cosimo Fanzago 1593-1678, Francesco Solimena 16571747, Ferdinando Sanfelice 1675-1748, Domenico Antonio Vaccaro 1678-1745, Luigi Vanvitelli 1700-1773 and Mario Gioffredo 1718-1785) in relation to that national. The study shows the architectural-scenographic construction and drawing techniques related to theatrical scenic illusionism of the seventeenth and eighteenth centuries in relationship with some Neapolitan monumental buildings; in particular the relationship between "optical illusion" and "theatrical illusion" spreads out in the urban cultural landscape through the plasticity of forms and architectural material subtraction (see Fanzago), the articulated architectural-visual combination of the transparencies of the staircases (see Sanfelice). In addition the develop of methodologies of intervention DSH (DeMorphogenesis, Semantic, Hypermedia Systems) - BIM (Building Information Modelling) to constitute both a multidisciplinary knowledge of classified $\mathrm{CH}$, that knowledge's dissemination for education. The objectives of the research are: 1) The construction of the "visual model" of documentation defined as "Digital Platform for the Knowledge's Representation" (DPKR) for reading, classification and comparison interdisciplinary data. It will be based on a process of deconstruction of the architecture (de-morphogenesis) and the definition of same elements's meaning following a new unified vision (Semantic Values). The process will allow to highlight: a) long-term regenerative synergies in order to promote an integrated project of "void spaces". b) phenomenological reading of the changing complexity of environmental reality with connections between the behavioural and physical structures of the place according to Christian Norberg-Schulz (1926-2000) and Kevin Andrew 
Lynch (1918 -1984); c) communication of the processes of modification of both the $\mathrm{CH}$ and the genius loci implemented for "typologies of representation"; d) hub solution of knowledge and simulcast description of information of $\mathrm{CH} .2$ ) The develop and experimentation of methodologies of intervention DSH - BIM with combination of solution "Scanto-BIM" for to rethink the idea of the museum that defines a new concept of "Smart Heritage". 3) The achievement of expressive values in the graphic study intended as a graphic language for the communication of architectural heritage project.

\section{METHODOLOGY}

The methodology of research is based on the construction of a visual model of documentation (DPKR) with the develop of solution DSH - BIM of "architectural interpretative values" of historical reality through a critical sensibility. Insertion of this solution in the communities is increased importance on modeling and representing buildings with wide variety of applications that includes applications for management of buildings and to create a 3D BIM representation. The BIM process allow integration of the design components (architectural, structural, plant, economic, etc.) in a single "environment" consisting of a model, favoriting interoperability among the various parties involved in the building process (Brusaporci and Maiezza, 2016). BIM, with its objects-oriented semantic organization, fosters $\mathrm{s}$ deep knowledge of the architectural asset through the creation of a shared information system, consisting of the database model itself (Garagnani, 2013). The reading the visual model (DSHBIM) highlight the processes of laceration in the urban fabric that influences the perceptive quality. The methodological operations will be based on the following research levels: 1) "Morphology of the Form" understood as retrieves's study of the sets's formal aspect through: a) the recovery of the perspective space and geometry; b) the succession of different cuts of the stage with long and short scenes; c) the turning "bibienesca" for corner's view; d) the input element realistic and philological. 2) "De-Morphogenesis of the Architecture" understanding deconstruction of the architecture by use of graphical analysis, deepening the connections of formal and constructive aspect. 3) "Semantic Values of the Architecture by On-Morphogenesis with Perceptive and Symbolic References" and the meaning's definition of the same elements following a new unified vision. 4) "Hypermedia Systems and Cloud Computing Platforms in the Processes's Representation of Codification and Valorisation of the Architecture".

\subsubsection{Research Level on Morphology of the Form}

The research level, based on the formal aspect signs of historical projects and monuments, illustrates the relationship between "optical illusion" and "theatrical illusion" in the scenic practice of the eighteenth and eighteenth centuries (national and Neapolitan School of Drawing). This couple will be found both in architecture, and in the urban cultural landscape through: 1) Plasticity of forms and subtraction of matter (see Fanzago). 2) Transparencies and visual illusion in the articulated monumental staircases (see Sanfelice). The connecting element between "optical illusion" and "theatrical illusion" is to be found not only on formal architectural innovations but above all in the relationships between the structural components and the space, where the perspective method has acquired a central role. It has undoubtedly revolutionized the architectural's design, provided the basis of the optical illusion and the vision of the spatial organization of the compositional elements of the project. For this reason, both the scenic practices introduced by Sebastiano Serlio (14751554), and the scene closed on three sides were analysed with regard: 1) The perspectival representation; 2) The alternation between long and short scenes with times and modalities of mutations; 3) The "corner view" introduced by Ferdinando Galli Bibbiena (1657-1743). 4) The introduction of the scenotechnical elements of space definition. Thus the optical illusion's in the comparison with monumental buildings of the Neapolitan School of Drawing. Serlio, that assimilates the term "Scenography" to that of "Perspective", in the Second Book of Perspectiva (1545) illustrates theories and procedures for creating perspectival scenes on inclined stages; the space will be defined univocally by scenes based on convention and relaism. Prepares, through a rereading of the schemes and experiences of Marco Vitruvio Pollione, Giuliano Giamberti da Sangallo (1445-1516), Antonio da Sangallo (1484-1546) and Baldassarre Tommaso Peruzzi (1481-1536 that used backdrops painted in two-dimensional perspective) - (Figure 1), the following codification of the three fixed-type scenes: 1) Comic in the street or market and made up of mounuments, civil houses, shops in late medieval style. 2) Tragic in a monumental square with ancient Roman style buildings enriched with colonnades, statues, obelisks. 3) Satirical in a sylvan environment with rustic huts (Figure 2). The scenographic structure will be based on: 1) "rectangular space" as in the model of Greek and Roman theaters with a scene placed at the ends and sitting position on degrading terrace. 2) "fixed (frontal) perspectival scene", unchanged for the theatrical duration, intially two-dimensional (consisting of a painted backdrop) and then three-dimensional (consisting of houses and wooden buildings of degrading dimensions). 3) inclination of the proscenium from the bottom to the top to increase the optical illusion of depth. 4) a perspective vision in flight towards the bottom, infinity space within the reach of the spectator. In the second half of the sixteenth century the stage space, with the contribution of the illusionistic system, will present itself in a "mixed mode": a "view from above" relative to the center of the palace hall (scene) and a "frontal view" (Italian) of separation between real space (room) and illusionistic (scene). The following projects included into this perspective are: 1) Andrea Palladio (1508-1580) for the Teatro Olimpico (Vicenza) with an anthropocentric perspectival view favored by the illusion of depth of temporary buildings by Vincenzo Scamozzi (1548-1616). 2) Bernardo Buontalenti (1531-1608) for the Teatro Mediceo (Florence) with: a) two areas for the representation (central and short side) inside a rectangular double-height hall with the central grand-ducal stage (of inclined stalls) and in the long sides the seats on terrace; b) the introduction of the variable scene with sliding backdrops on lateral retractable guides (Figure 3). With regards to the late Neapolitan Renaissance architectural production, the architect Domenico Fontana distinguished itself for the engineering characte and quality of the works. $\mathrm{He}$ worked at Rome and Naples; in the latter moved in 1592 to the service of the Spanish viceroy Conte di Miranda where he was commissioned to design the new Royal Palace. Another significant work is the church of Santa Maria della Stella (1571). In 1637 Bartolomeo Picchiatti (pupil of Fontana) built the façade finished, in its final aspect, by Domenico Antonio Vaccaro in 1734 (Figure 4). 

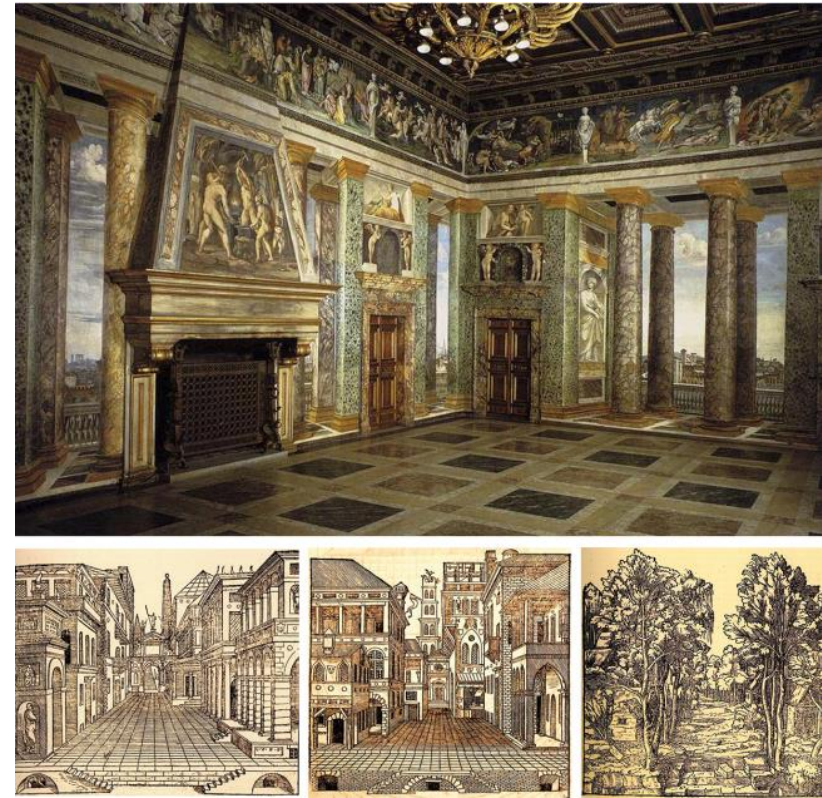

Figures 1, 2 - From top left, Sebastiano Serlio, Tragic, Comic and Satirical scenes. Baldassare Peruzzi, Perspective view of the Sala delle Prospettive, Villa Farnesina, Rome, 1515-17.
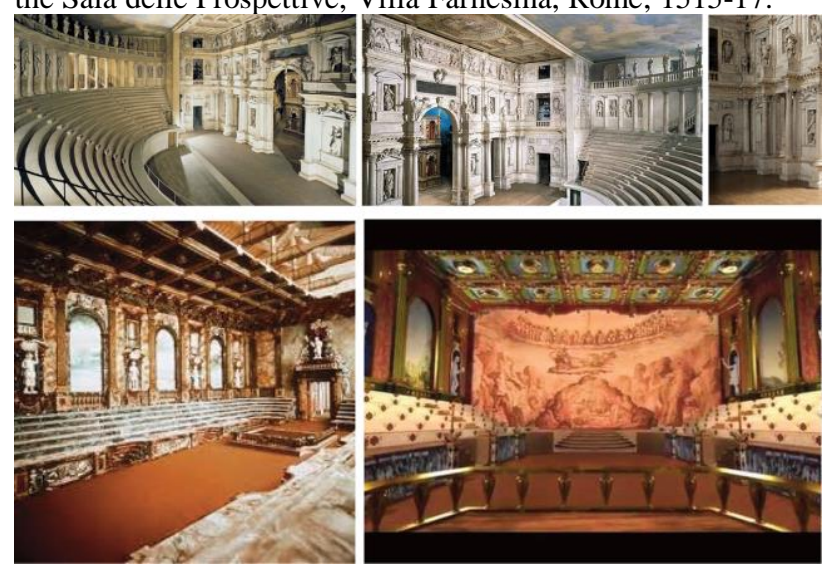

Figure 3 - From top left, Andrea Palladio. Olympic theater of Vicenza, 1580-1584. Bernardo Buontalenti. Teatro Mediceo of Florence. 1586.
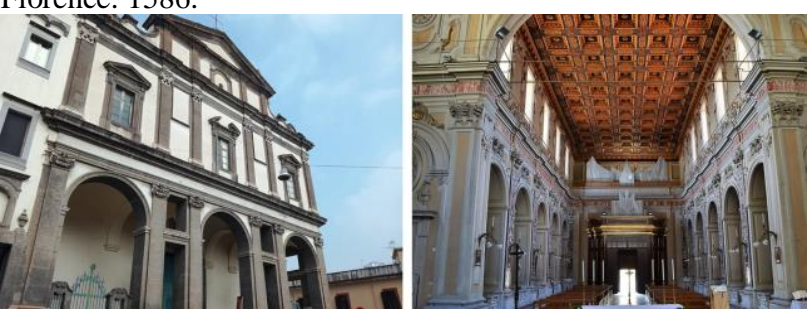

Figure 4 - From left, Domenico Fontana, Santa Maria della Stella's church (1571), finished in 1734 by Domenico Antonio Vaccaro.

The internal alternation mode with sequence of long scenes articulated by pillars clearly shows an optical-visual balance guaranteed also by the upper windows. At the beginning of the seventeenth century, the scenic practice, divided between research and routine without application in daily practice, reproduces schematizations and multiplication of archiectural environments up to the advent of the "multi point perpectives" and the "corner view". The perspective studies of Guidobaldo del Monte (1545-1607), Ludovico Cigoli (1559-1613) and Scipione Chairomonti (1565-1652) contributed to this.
Emblematic figure of renewal is Marcoantonio Chiarini (16521730) through long symmetrical scenes in closed environments (Forza della Virtù, 1694; Nerone fatto Cesare, 1695) and the introduction of architectural elements (pillars, columns) to mark the obsessive spatial rhythm (see you the Galleria delle palme, 1694) - (Figure 5). Cosimo da Fanzago (sculptor and architect, active mainly in Naples) is an exceptional figure of the Neapolitan School of Architectural Drawing of the seventeenth century; it is bearer of a culture between late Mannerism and Baroque. Innovative figure of the Neapolitan Baroque for: 1) Technical skills in the field of marble, stone, stucco and metal. 2) The introduction of classical composition elements but at the same time original for naturalness and combination of cultural contributions. 3) The supremacy of the constructive aspect over the expressive one. 4) The monumentality of constructions in which visual perception and aesthetic theory are structural parts of the complex system of recognition and translation. 5) The use of sinuous and complex forms, plastic and scenographic to favor architectural theatricality and optical illusion, effects of light and shadow in the dimension of the urban landscape based on decorative exuberance and the drama expressive. Particularly evident in the churches's facades of San Giuseppe in Pontecorvo and Santa Maria degli Angeli alle Croci (Figure 6). The latter placed, according to theatrical tradition of the sixteenth century, in a central perspective view at the end of the inclined street level of the access and with a rhythm of the vertical elements to highlight the space. Also interesting are the churches of Santa Maria of Costantinopoli, Santa Teresa a Chiaia, Santa Maria Maggiore (the Pietrasanta), San Giorgio Maggiore, Basilica of Santa Maria Egiziaca in Pizzofalcone (which inspired Borromini for the project of Sant'Agnese in Agone, Rome) and in the palaces of Zevallos, Carafa di Maddaloni, Donn'Anna. 6) a planimetric structure of the Greek cross churches with a longer longitudinal axis than the other, symmetrical staircases and large portico with arcades, according to the early Christian setting. Clear is the parallelism to theatrical scenography with a sequence of long symmetrical scenes based on the introduction of architectural elements to divide the space and increase the charming sense. 7) a strongly vibrant façade system thanks to the emptying of the architectural masses to make place at statues and the side central windows. In the eighteenth century theatrical scenographies reproduce ideal models with the following baroque stage features: 1) Perspectival view aligned with the proscenium, about one meter and a half from it.

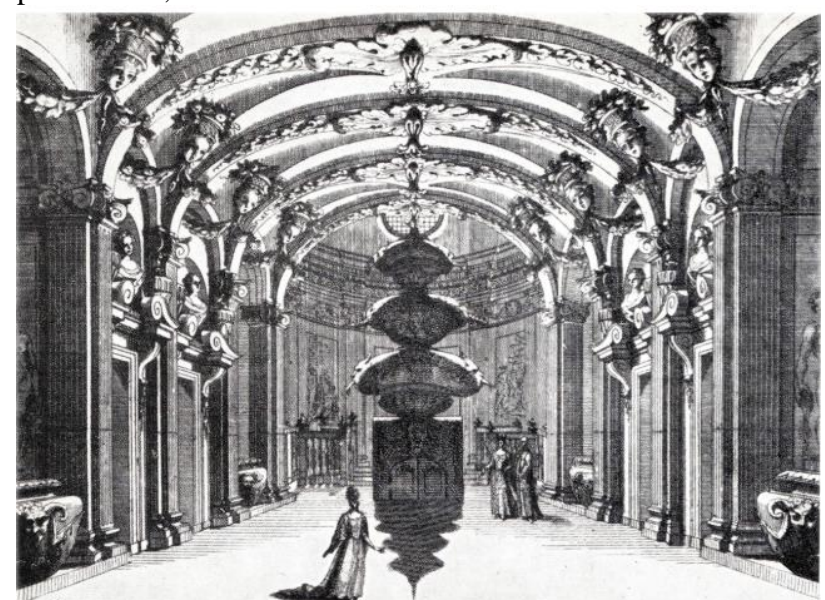

Figure 5 - Marcantonio Chiarini. Galleria delle Palme, 1694. 
2) Transgression by some authors of the uniqueness of the central convergence point for the cuts's organization of the canvases and of the scenic striking distance; things can be found in Ferdinando Tacca (1619 -1688). 3) Observer placed higher than the stage, unlike the past placed in the area reserved for the prince. 4) New visibility favored by perspective deformations for the position of the spectators. 5) Composition in the central unit with the stylistic and iconographic elements of the lyric theater, framed between two foreground scenary flat to favor the "framework scene" of Juvarra (based on a perspective cage of city, forest and covered atrium) and representation with multi point perpectives. In this period emerging author is Ferdinando Galli Bibiena (16571743); the drawings published in "The civil architecture prepared on geometry and resolved to the perspective" (1711) and "Directions to Young Students in the Drawing of Architecture" (1777) introduces: 1) The 69 operation. 2) The scene perspective's types: with multi point (for scene shifting in the outer space) and corner view intended as a diagonal crossing of the proscenium according to the trajectory of the canvases to exalt evocative capacities, excluding part of the space represented. 3) The sloped of the proscenium in the tenth part of the length of the stage. 4) Position of the observer's point of view instead of characters. 5) Drawing of the architectural elements on the canvases in perspective, through straight lines drawn parallel to the horizon. 6) "Braccetti" to calculate the perspective reduction of the measurement unit. 7) balanced scenic image between perspective vision and spectators vision in which the close up architectures are at the same time dilated in an articulated illusionistic system to capture the view of the spectator. (Figure 7). Filippo Juvarra is another important personality of the eighteenth century with designs that will highlight: 1) A graphic representation, anticipatory the pictorial-luministic eighteenth-century school, will be based on the alternation of light and shadow to comprehension the elements. 2) Scene's scaling based on the profile of the scenic arch in consideration of the proportions of the real proscenium. 3) Exaltation of the architectural structure on that perspective. 4) in the architectural plan the operative rule for the frequency of short and long scenes predisposed for the canvases. This in order to facilitate the scenes, the operation of the mutations and the alternation of scenes open to enclosed spaces. Also Pietro Righini, Italian architect and scenographer, is active in the first half of the eighteenth century in Turin, Parma, Naples with a representative-scenic language different from that of Bibiena, Juvarra and Vanvitelli. In fact the compositions: 1) are static and not vibrant in the sign (as in the case of Vanvitelli). 2) they are represented with different visual languages and scenotechnical methods such as: a) use of canvases only for close-ups, of those broken along the diagonals and extended in the perforated backdrops; b) the possibility of verifying the means adopted for mutations at the change of scene; c) the alternation of long and short scenes (Figure 8). In Naples Francesco Solimena, Ferdinando Sanfelice, Luigi Vanvitelli and Mario Gioffredo are exceptional figures of the Neapolitan School of Architectural Drawing of the eighteenth century. In particular Solimena, Sanfelice and Vanvitelli will use the logic of scenicperspective-illusionistic drawing to highlight a representative analytical-aesthetic language to support the creation of urban space. Solimena, painter and architect, is active in Naples; he is considered one of the most illustrious Baroque tradition's exponents for complex scenographies. These will become the distinctive feature of the artistic production after 1680 .

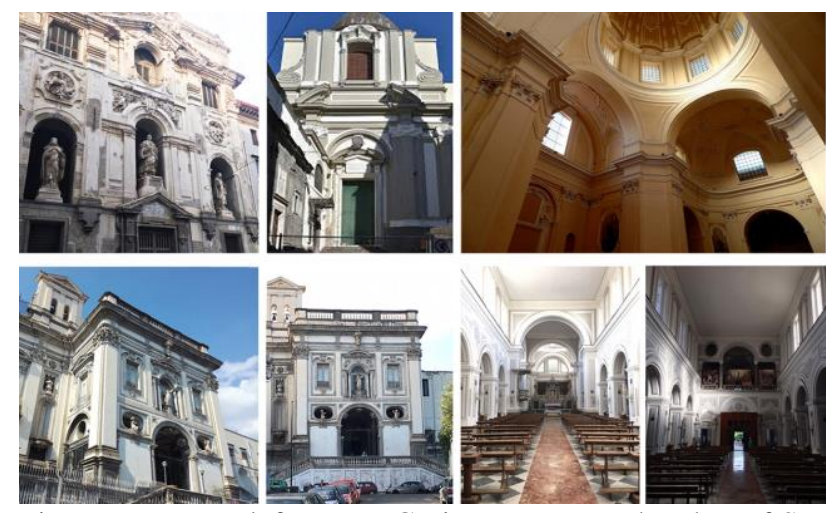

Figures 6 - From left to top, Cosimo Fanzago, churches of San Giuseppe in Pontecorvo, Santa Maria Maggiore (Pietrasanta) and Santa Maria degli Angeli alle Croci, Naples.
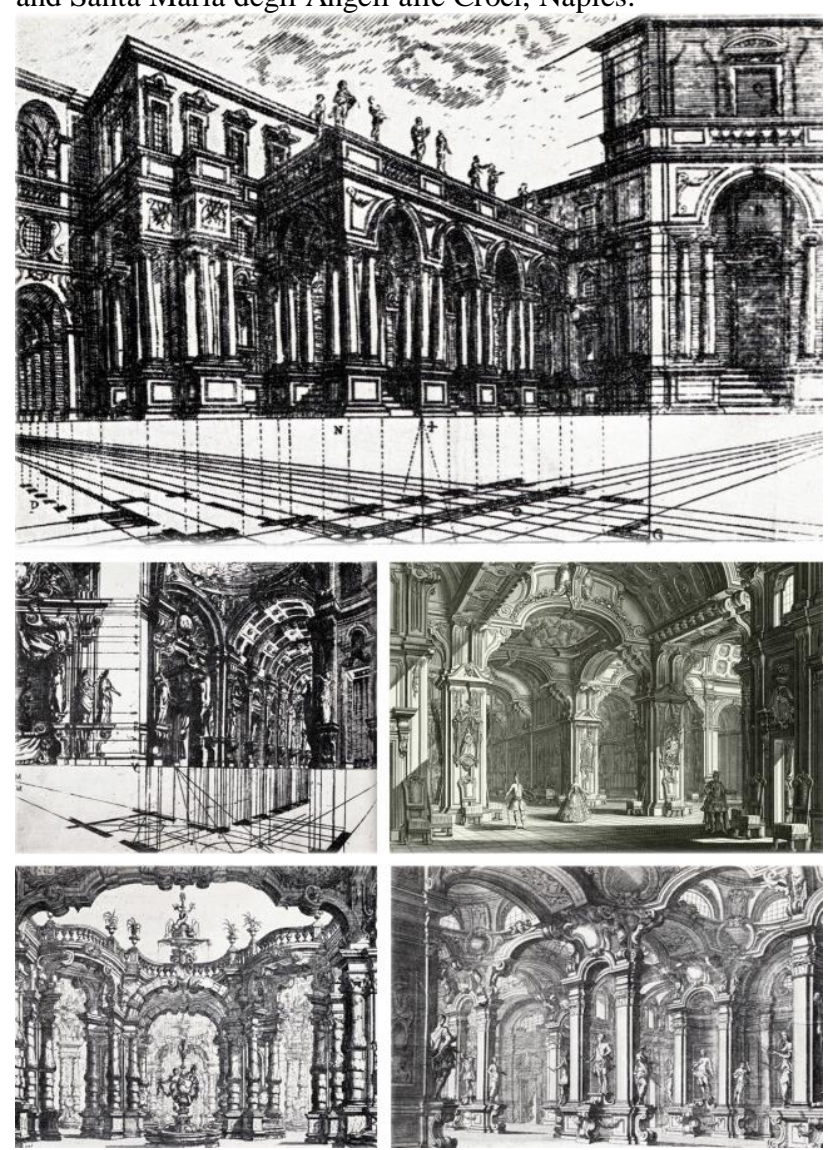

Figures 7, 8 - From top left, Ferdinando Galli Bibiena, Scenes with multi point perpectives and relative optical illusion in Direzioni della Prospettica Teorica Corrispondenti a quelle dell'Architettura, 1732. Pietro Righini, Medo di A.L. Vinci, Parma, 1728 .

The Palazzo Solimena is extremely characteristic. Also Ferdinando Sanfelice (painter, architect, creator of festival machines for civil and religious ceremonies) is considered a further exponent of the late Baroque culture active since the XVIII century. His cultural background, favored by his relationship with Francesco Solimena, has been strongly focused on the figures of Fanzago and Borromini. This will allow him to formulate an architectural-compositional language with multiples architectural codes, oscillating between classical and rococo culture. Therefore, each element is elaborated through a accurate analysis of its details, favored by the introduction of decorative and structural solutions. In the 
drawings is clearly visible: 1) The artistic language and structural and decorative character of the interventions. 2) The principles of Baroque architecture; in particular sinuous and complex forms, sculptural element of the facades; in addition the sense of theatricality through decorative exuberance/expressive drama (strong plasticity and optical illusion) and alternation of long and short scenes in the verticality of the architectural composition. 3) The optical illusion accentuated by multlipes details and graphic technique used. In particular the pictorial definition is intended as information relating to the solutions adopted in painting by Solimena. 4) The graphic methods and design intrinsic to the drawing intended as a definitive study. 5) Elevation's typologies of the design variations (ideative and executive phase). 6) Types of figures adopted and project idea. Emblematic project are: 1) The façade's study of the church of San Lorenzo Maggiore (1742). 2) The triumphant apparatuses for the church of San Lorenzo Maggiore and altar study. 3) The Palazzo Sanfelice (1724-28), majestic residence of his family, in which the compositional structure presents windows on the main floor of the façade with flat tympanums in the part of the balcony and circular where the windows are located; while on the second floor are present decorations with round arch towards the outside and in the center are arranged roundels with busts. The courtyards constitute the theatrical-illusionistic scenographic whole with the architectural-spatial system of the staircase; this according to the vision of the transparency of the forms for a complex vision. Then the "void space" is reflected within the courtyards scene: the first (octagonal) allows access to the vestibule with the grandiose staircase that reproduces the inclination plane of the octagonal walls; the second (rectangular) presents the "hawk's wings" staircase of "theatrical-scenographic representation" to the back garden. Palazzo dello Spagnuolo (1738) in which the plastic interpretation of the space and the elegant style found their culmination in staircase "hawk's wings", as in Pompeian painting (Figure 9). Also Domenico Antonio Vaccaro (painter, sculptor, architect and a pupil of Solimena) was an artist established between the Baroque and the Rococo in the design of monumental Neapolitan churches. Through the experience with Solimena he come into contact with Sanfelice; the latter will contact him for the church of Santa Maria delle Dame Monache of Capua's construction. During the period of artistic maturity he was charged of the following projects's realization: 1) in 1718 the church's model of Santa Maria della Concezione in Montecalvario with Giuseppe Lucchese Pezzolini (16781724) and Filippo Marinelli; the latter is considered one of the most interesting examples of Neapolitan Baroque architecture. 2) of the Church of San Michele Arcangelo. 3) in 1731 of the Princes's Palace of Roccella, of the Santa Maria di Costantinopoli's church; as well as the Spinelli Palace. 4) In 1734 he worked at the Santa Maria del Rosario's church. 5) Immacolatella Palace. 6) Santa Maria della Stella's church (only completion) - (Figure 10). The affinities between Luigi Vanvitelli and Juvarra are surprising; it is another exceptional figure at the end of 1700, designer of the Royal Palace of Caserta. The theatrical aspect can be found in the rigorous construction of the architectural elements within a framework of prospective scenic research; the work "Carcere", that recalls the Room of Juvarra, is an example of compositional tension based on the central pillar (central visual node), from which the galleries and staircase of the upper floor branch off, according to the diagonals. His mastery in the ink drawing watercolor (see School of Carlo Fontana) is well-known, the sign is safe and fast. He accentuates the color contrasts with watercolors, creating a symbiotic relationship between painting and architecture. The space is represented in a vedutistico mode thanks to his father Gaspar teachings, clearly oriented towards a vedutistica optical-perspective; also, he shows how architecture should not be defined only through outer space but also in its details, such as a decoration. Vanvitelli will focus on the following aspects: 1- perception and analysis for the possession of the space. 2- space is only one (no distinction between natural and ideal space, pictorial and architectural space). 3- Spectacular or fantastic space is one that does not differ from the natural space (see Juvarra, Piranesi where there is a close relationship between spatial figurative fantasy and concrete architectural reality) - (Figure 11).
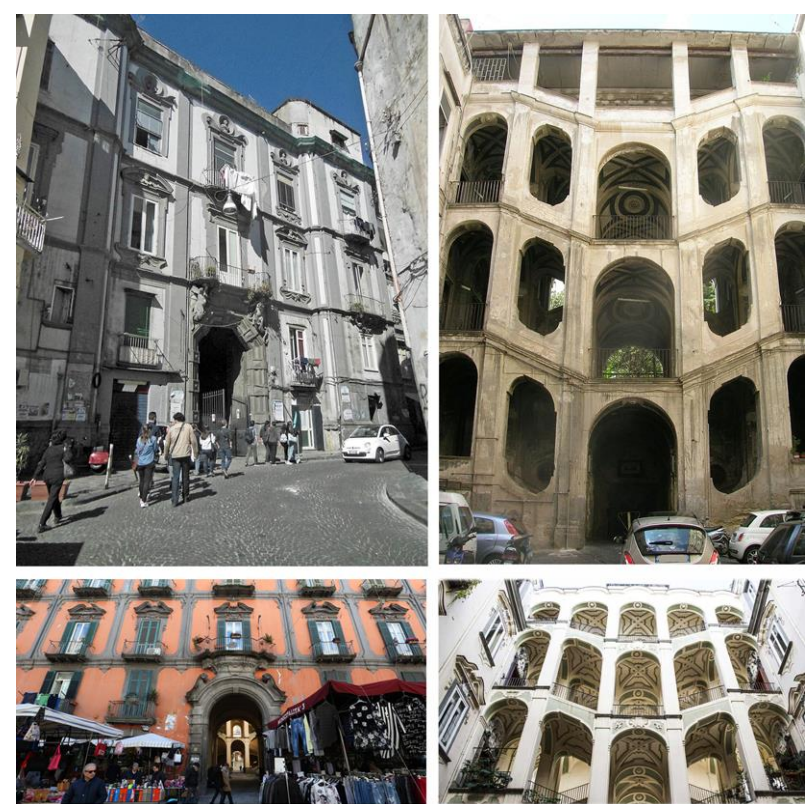

Figure 9 - From top left, Ferdinando Sanfelice, Sanfelice Palace, 1724-28. Palace of the Spagnuolo, 1738, Naples.

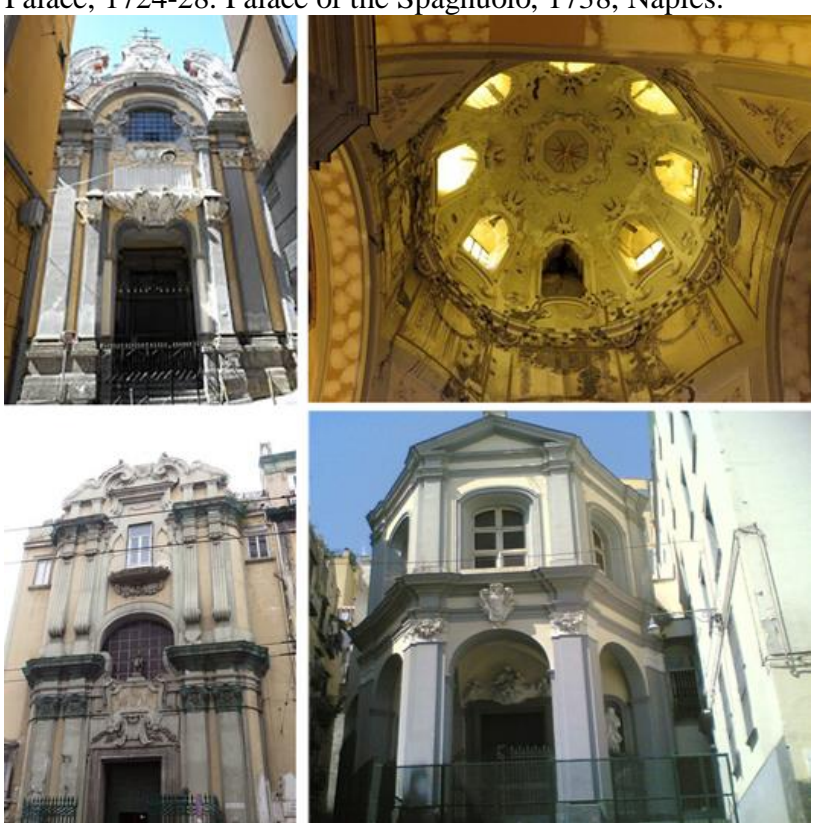

Figure 10 - From top left, Domenico Antonio Vaccaro, Santa Maria della Concezione in Montecalvario with dome's interior, San Michele Arcangelo and Santa Maria del Rosario in Portamedina churchs. 

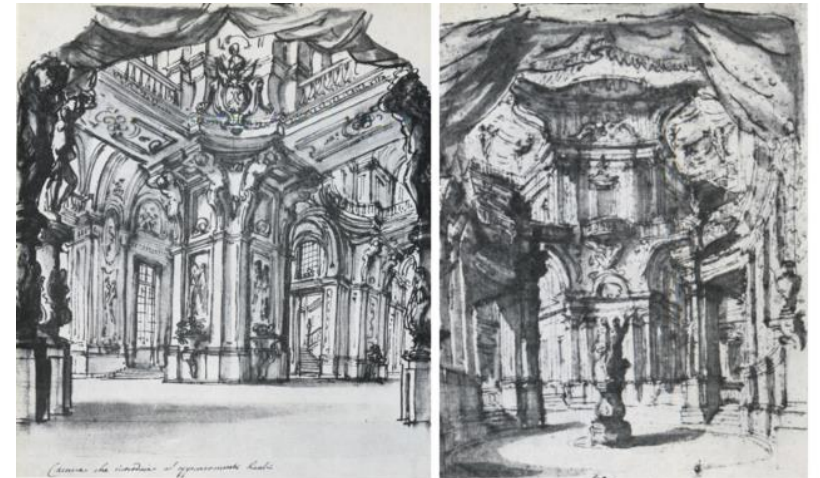

Figure 11 - Filippo Juvarra, Camera che introduce ad appartamenti reali, Luigi Vanvitelli, Naples, Italy.

Mario Gioffredo is active in a Neoclassical style and is called the Neapolitan Vitruvius. He has been an innovative architect in the graphical representations thanks a frequentation with Solimena as well as being an Italian engineer, engraver and topographer. Designer of the Spirito Santo's church and other churches as well as the Cavalcanti Palace.

\subsubsection{Research Level of Architectural De-Morphogenesis}

The morphogenesis allows to acquire, through graphic analysis and comparison of data and samples, thresholds of elements in the process of generation of the forms. Knowledge rendered not only by "digital morphological combinations", but also by the interpretation of existing data (according to the ICOMOS 2013, UNESCO 2011 directives) as a critical vision. Relevant to today's times of "digital transformation" and "digital modernization policies" is the introduction of the digital "demorphogenesis"; method that, as the de-construction, allows "critical's spaces of representations" for existing data.The deconstructive method, however, is based upon analysis via deconstructionist concepts; it seeks to put forward the existing signs of creativity by following various traces (Gur, 2008). DeMorphogenesis concept, instead, acquires the results obtained by graphical analysis (De Masi, 2017) and proposes advances in the field of: 1) Graphic methodologies of Cultural Landscape's identification. 2) Methods of digitization, detection and visual evaluation of the landscape and architecture's morphological features. 3) Interoperable models application for analysis and evaluation of heritage. 4) Communication of landscape modification processes for visualperceptive regeneration as a remedy for urban degradation. The following diversified categories define the formal structure: $\mathrm{C} 1$ "Representation Level of Landscape Elements's Identity" for understanding of Entirety, Criticality and Vulnerability aspects with the following significance subcategories: SC1.1 "Physiotopes" in order to define different types of landscape. SC1.2 "Open Space" consisting of open spaces identification. SC1.3 "Anthropological Semiology" in order to define infrastructural, settlement, cultural, historical, architectural sign of arrangement, management of the historicized landscape and the articulation of the Urban and Rural Historical Landscapes of the environmental mosaic. SC1.4 "Absolute Visualisation" that allows the display of the great lines of the perceptible landscape about the overall set of morphological aspects present. C2 "Visual Representation Level of Landscape with the Evaluation of the Morphological's Characters". In particular the study the forms of the ground, the distance and position of the observer according to Kevin Andrew Lynch
(1918-1984) and described by following subcategories: SC2.1 Visual Planes (succession of elements in the space). SC2.2 Visual Cones (distinguished by dimension, depth, orientation). SC2.3 Main reference points (useful elements for orientation and localization). SC2.4 Delimited Visual Scopes (limited and enclosed view). C3 "Architectural Representation Level of Characters's Anamorphosis" with the following significance subcategories: SC3.1 "Graphic Lexicon Components" to highlight shape and tonal value, pattern, texture and background. SC3.2 "Chiaroscuro Lexicon Techniques" to obtain special effects with pencil, inks, charcoal and sanguine by regular and cross hatching, dot technique, frottage and graffito (Figure 12). SC3.4 "Chromatic Lexicon Technique" by the use of different color modes and colors in a monochrome design or in a scheme in which another one predominates (Figure 13). SC3.5 "Application Areas of the Techniques" with connection to the architectural finishes (of elevation, section and perspective), to the centers of visual attention, to the spaces between elements, to the contrasting elements in a set of regular elements (Figure 12). C4 "Architectural Representation Level of Identities and Syntax Morphological" with the following significance subcategories: SC4.1 "Cultural, historic, scientific and social". SC4.2 "Aesthetic" (scale, colour, texture, style, technical excellence, quality). SC4.3 "Integrity and Continuity". SC4.4 "Identity Characters, Preexistence and Utilizations".
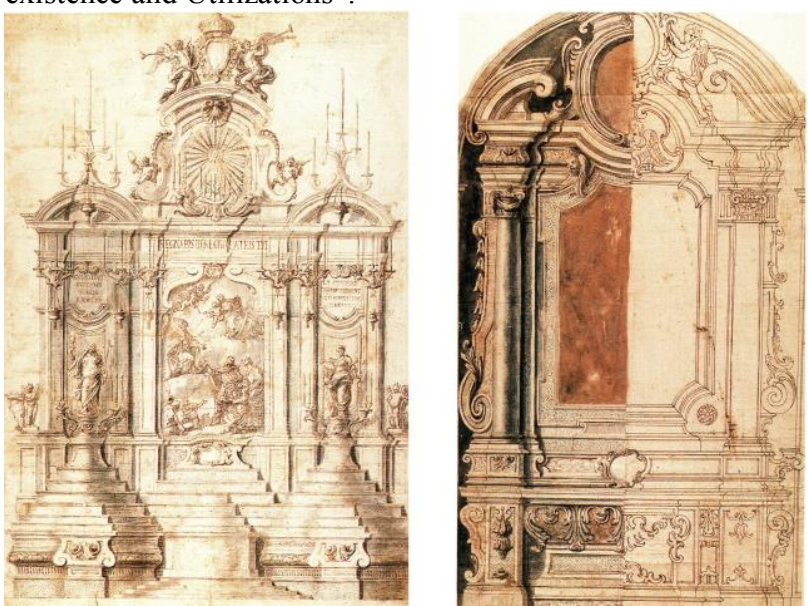

Figure 14 - Ferdinando Sanfelice, from left, Drawing of the triumphal apparatus for the church of San Lorenzo Maggiore in Naples and Study of Altar.

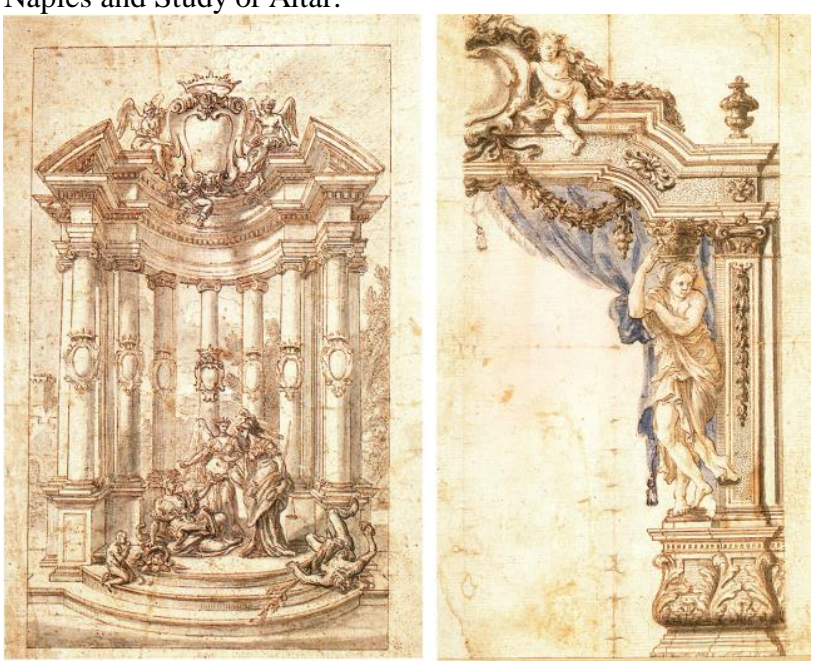

Figure 13 - Ferdinando Sanfelice, from left, celebrate's apparatus study and portal with decoration. 
SC4.5 "Function of the space" with natural lightning and orientation. SC4.6 "Formal Composition's Analysis" (harmony, symmetry / asymmetry, modularity, rhythm, alignment, visual direction, movement, balance, proportion, visual weight, visual unity, visual contrast). SC4.7 "Geometrical and proportional study of Architectural Elements". SC4.8 "technological structure". C5 "Dimensional Representation Levels" with the following significance subcategories: SC5.1 "Study of sources, the arrangement of indirect survey techniques and the relevant approach of the survey". SC5.2 "Study of the survey integration methods applied to the plan and the elevated parts in order to define a one-3D system". SC5.3 "Selecting an appropriate 3D acquisition methodology"; SC5.4 "Integrated digital survey and data recording" to highlight the irregularities of the building. Metrological and proportional analysis allowed for the optimization of the modeling operations, and the knowledge of the complex, just partially documented (Lawrence, 2019). SC5.5 "Dialogue between the different methods of analysis and $3 \mathrm{D}$ modelling their of the area of representation with the multiplicity of data collected. C6 "Scalar Representation of Sensitivity Levels" with Visual Model of historical signs and knots for to read of patterns related to typologies of representation, modifications and evaluations of data within the area interest.

\subsubsection{Research Level of Semantic Values of the Architecture by On-Morphogenesis with Perceptive and Symbolic References}

The research level allows both a recomposition of the formal architectural vocabulary (lexicon) in a new vision of transformation, and of the intangible aspects linked to the cultural landscape. Therefore, for each category of the previous paragraph, the following analysis will take place: C1 "Semantic Representation Level of Landscape Elements's Identity" in order to define relationships among the different architectonic emergencies and green spaces and with the following significance subcategories:SC1.1 Construction/Context/Spaces. SC1.2 Objects. SC1.3 Perception Visual Analysis with the highlighting of indicators. SC1.4 Rarity. SC1.5 Representativeness/Uniqueness. SC1.6 Diversity. C2 "Semantic Visual Representation Level of Landscape with the Evaluation of the Morphological's Characters" described by following categories: SC2.1 "Visual Margins/Barriers" (relative to observer distance, height and consistency) according to Lynch. SC2.2 "Visual Centre" for depth and persistent concentration of significance related to the genius loci. SC2.3 "Visual Obstacle Elements" (contrast, color inconsistency, shape, weaving, dimension) according to Lynch. SC2.4 "Integrity and fragility of open and closed urban spaces" (Ferrara \& Campioni, 1997). SC2.5 "Permeability of constructed environments" (Ferrara \& Campioni, 1997). SC2.6 "Porosity of anthropic environment" (Ferrara \& Campioni, 1997). SC2.7 "Environmental disorder" (Ferrara \& Campioni, 1997). SC2.8 "Integrity and connection of spaces to green" (Ferrara \& Campioni, 1997). SC2.9 "Significant environmental attractors" (Ferrara \& Campioni, 1997). C3 "Semantic Architectural Representation Level of Characters's Anamorphosis" with the following significance subcategories: SC3.1 "Reading of the architectural finishes (of elevation, section and perspective), of centers of visual attention, of spaces between elements, of contrasting elements. C4 "Semantic Architectural Representation Level of Identities and
Syntax Morphological" with the following significance subcategories: SC4.1 "Signifier/Signified" that as has been acknowledged by Saussure (1915), the signifier and the signified are inseparably tied together, although the relationship is contextually and arbitrarily conventionalized (Durmus and Gur, 2011). SC4.2 "Intrinsic" in order to define authenticity and completeness. SC4.3 "Estrinsec". SC4.4 "Intangible Values" including appropriateness, ambiguity, modernism, visual power, intellectual elegance, timelessness, accumulated value, arbitrariness, marketing (Vignelli, 2012). SC4.5 "Tangible Values" including relationship between bodies, contrasts of size, scale, surfaces, color, sequence, identity and diversity (Vignelli, 2012).SC4.6 "Associative". SC4.7 "Aesthetic attributes". SC4.8 "Existence of conventions and planning rules". SC4.9 "Lexicon of Elements Typological and Structural" for the recognition and evaluation of the identity character of Separation, Contact, Overlap, Combination, Reduction, Coincidence (De Masi, 2017, 2018). SC4.9.1 "Syntax of the functions, combinations and composition of elements". SC4.9.2 "In-Beetwen" (Grosz ed Eisenman, 2001), movement field of architectural theories that, according to Durmus and Gur, 2011, are regulated by criteria as structure/decoration, abstraction/figuration, figure/ground, form/function, interior/exterior. SC4.9.3 "Function/form, plan/volume, marginality/centrality, served/servant, fixed/flexible, stable/flowing, repetitive (iterable)/unique, fit/misfit, discovered/invented, concept (mind)/vision (body), material/transcendental, concept (referent)/sign (Durmus and Gur, 2011). C5 "Semantic Dimensional Representation Levels" with the following significance subcategories: SC5.1 "Thematic plans of relationships integrated with the processing data both in the area of interest landscape and in the landscape unit" SC5.2 "Lexicon of size, scale and proportion aspects with the reading of the formal and dimensional elements through".

\subsubsection{Research Level on Hypermedia Systems and Cloud Computing Platforms in the Processes's Representation of Codification and Valorisation of the Architecture}

The C6 level "Hypermedia Systems and Cloud Computing Platforms in the Processes's Representation of Codification and Valorisation of the Architecture" with Autodesk's A360 and BIM 360 refers to the European Union Public Procurement Directive 2014/24/UE. It allows of visualization content, the dialogue between different 3D modeling, add and compare new data and communication of modification processes through virtual reality applications of Cloud Computing Platforms not only for new construction interventions but also for architectural restoration works. The visual model (morphological lexicon and conservation database), linked to ICT (Information and Communications Technology) solutions, is a "web-oriented" HBIM system with related application information models. It will be implementable, articulated with digital tematichs sheets divided into informational categories and linked to a database (Figure 14). This in order to favor: 1) Interaction, sharing, improvement of knowledge, exchange of multidimensional information, transition from parametric representations to objects integrated into $3 \mathrm{D}$ web through manipulation of intrinsic (dimensional, geometric, morphological and chromatic) and extrensic data. 2) Creation of 3D elements by geometry, semantic representation and appropriate correspondence; 3) Creation of libraries of parametric objects based on point clouds. 


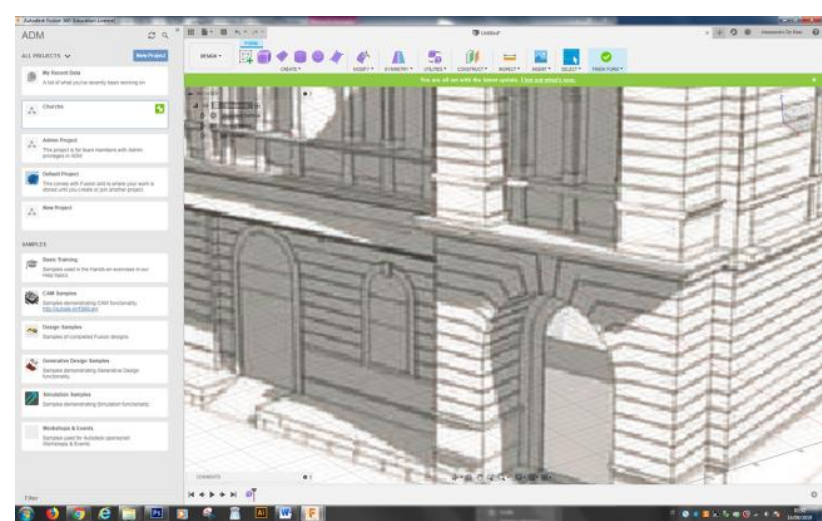

Figure 14 - Cloud Computing Platforms: Autodesk Fusion 360.

The algorithms will allow the representation of plane surfaces or primitive geometries in consideration of the automation by numerical model (point clouds) to a parametric model is still under study. 4) Combination BIM systems with GIS data storage and management software; 5) Hierarchy of digital levels and multimedia contents discretized by $2 \mathrm{D}$ and $3 \mathrm{D}$ models interoperable and subdivided by dimensional categories and meanings. 6) representation of permanence signes, modifications and subsequent comparing data of different functional, historical, geometric, typological and structural categories with topological, photometric and geometric characteristics (De Masi, 2008). 7) re-think the relationship between perception and representation for the purpose of sharing aspects understood as relevant aspect of the knowledge of the contemporary city and to the understanding of urban reality in the twenty-first century. The visual model includes the following categories: SC7.1 "Simulation Lexicon" intended as "Digital Restitution and Modeling" with the creation of an integrated 3D system of dimensional and formal data manipulable for the purpose of preservation and checks geometry, topology and photometry data (De Masi, 2017, 2018). In particular, focusing on the built heritage, the 3D model favors a communicative and multidirectional flow where information of different nature participates in the message creation (Brusaporci et al., 2017). It includes the study of scale changes in the individual models (site, architecture, details) with simplifications based on the selection and activation of geometric information from different nominal scales. The modeling of irregular shapes, carried out after having performed sections on the numerical model, was the most complicated process; it was necessary to consider intrinsic data, implement discretization in the modeling phase and verify the articulation of the buildings. I proceeded for the simplest models by examining the scholars Biagini et al., 2016 that have linked numerical modeling with that in the BIM software; however building 3D models of elements, first on recurrent geometric structures and then by simplifying the geometric structure. SC7.2 "Lexicon of representative Typology of Models" intended as "Diversification of 3D graphical models" appropriate to represent the work and its space with the communication of modification processes occurring in time (Figures 15, 16, 17). It includes "Diachronic equipment" and "Synchronic equipment" queried, to highlight the differentiation data and the modifications occurred (De Masi, 2018). It will be based on digital integrated survey (3D laser scanner time of flight model Leica C10 ScanStation) and Structure from Motion for data search of topography, laser scanning, photogrammetry, H-BIM, matching the model and the point cloud, designing parametric building elements
(Figure 18). SC6.3 "Digital lexicon" for reading of the various modification and additions that occurred in buildings, through the different functional, historical, geometric, figurative, chromatic, typological and structural categories. It contains critical considerations and elements of innovation (Figure 15).

\subsection{Result and Conclusions}

The parametric modeling in the DSH - BIM solution, intended as a process of synthesis of real data, allowed to highlight: 1) the Lexicon (set of formal rules for architecture reading), the Syntax (set of formal rules for the grammatical / compositional language of architecture relative to geometric, cultural, historical, theoretical and symbolic data), Semantics (set of meanings of architectural elements). 2) The repercussions on representative typologies / categories by obtained's data use.

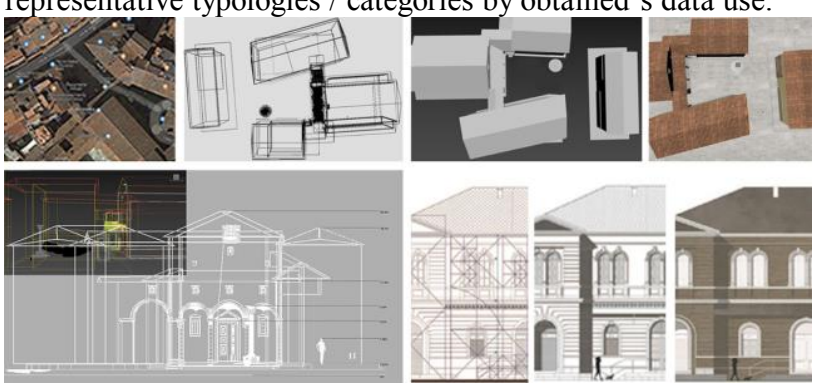

Figure 15 - Analysis lexicon "De-morphogenesis": horizontal and vertical structures.
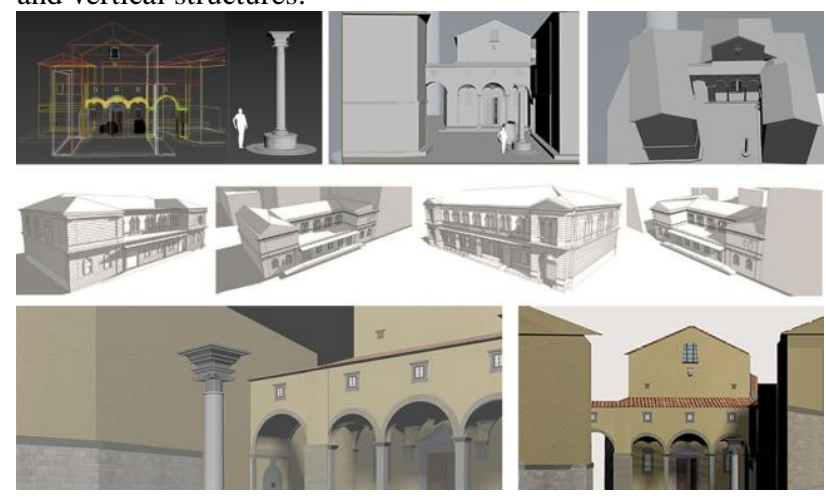

Figure 16 - Structures area: reconstruction with BIM methodologies.
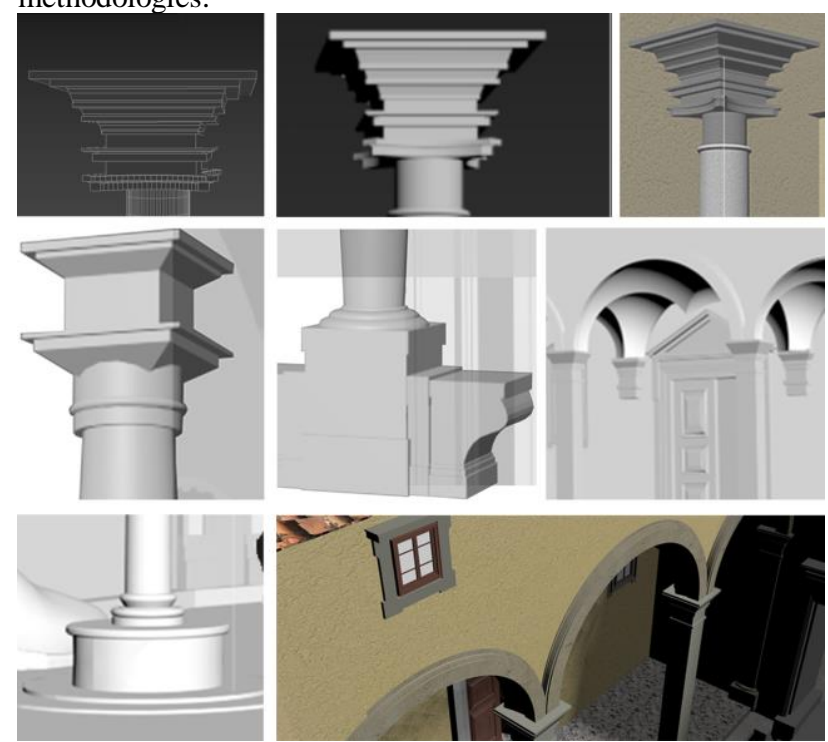

Figure 17 - Elements architecture recostruction with Ondemorphogenesis and texture layering. 

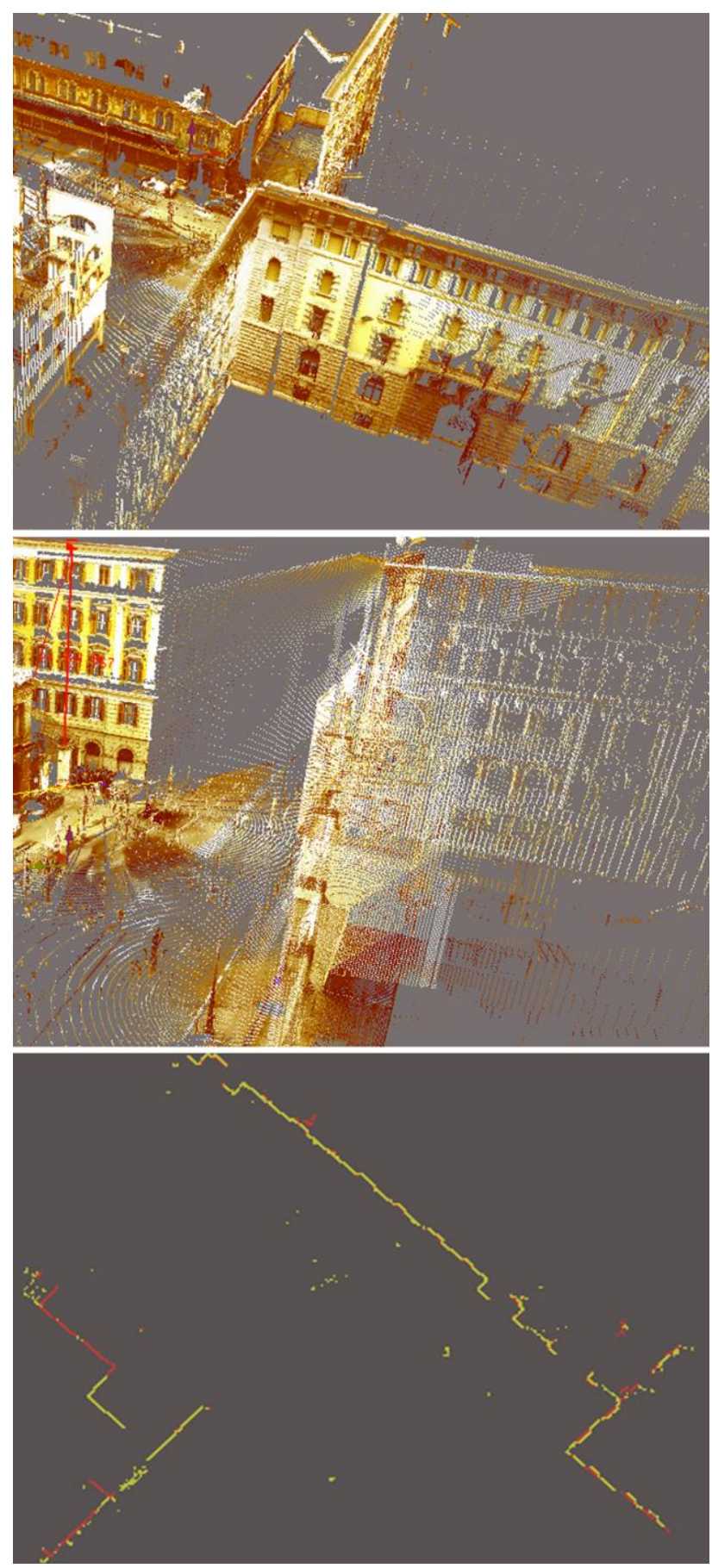

Figure 18 - Numerical model with RGB reflectance.

3) The solutions adopted are useful for the chronological verification and the state of conservation of a monumental building. This with regard to the analytical principle of "existing de-morphogenesis" and "reconstruction with integrated parametric data". Among the objectives achieved is found: 1) Methodologie of intervention DSH - BIM with combination of solution "Scan-to-BIM" in the historical reality. This to rethink the idea of the museum as virtual territory that defines a new concept of "Smart Heritage" and to constitute a multi-disciplinary knowledge of classified CH. 2) Solutions that includes applications BIM for management of buildings; 3) Manipulation of the elements based on dimensional parameters. 4) Knowledge and communication of $\mathrm{CH}$ and the genius loci. 5) Open source applications intended for an exploration service of $\mathrm{CH}$. 5) Realization of 3D parametric digital models with appropriate stylistic features in the same way as reverse engineering solutions. 6) Reconstruction of scenographies based on the graphic "operative" methods of the theater men in order to reconstruct the perspective view of the scenes. The conclusions show that is necessary to develop protocols; this becauseas the BIM was not designed for morphological reading of the existing $\mathrm{CH}$.

\section{REFERENCES}

Australia ICOMOS, 1988. Guidelines to the Burra charter: cultural significance.

Brusaporci, S., Ruggieri, G., Sicuranza, F. and Maiezza, P., 2017. Augmented Reality for Historical Storytelling. The INCIPICT Project for the Reconstruction of Tangible and Intangible Image of L'Aquila Historical Centre, MDPI.

Brusaporci, S., Maiezza, P., 2016. Re-Loading BIM: Between Spatial and Database Information Modeling for Architectural Heritage Documentation. In: AA.VV. Dibujar, Construir, Sonar. Investigaciones en torno a la expresion grafica aplicada a la edificacion. Tirant Lo Blanch, Valencia, 835-847.

Biagini, C., Capone, P., Donato, V., Facchini, N., 2016. Towards the BIM Implementation for Historical Building Restoration Sites. Autom. Constr. 71, 74-86.

Cantone, G., 2002. Napoli Barocca, Napoli, Laterza.

Ceci, G., 1921. Il primo passo di Cosimo Fanzago in Napoli Nobilissima, S.N., II, pp. 142-143.

Durmus, S., Gur, S. O., 2011. Methodology of deconstruction in architectural design, ScienceDirect, Procedia Social and Behavioral Science, Elsevier.

D’Agostino, P., 2011. Cosimo Fanzago scultore, Paparo Edizioni, Napoli, pagg. 494.

De Masi A., 2008. Campania (Italy), Cultural Landscape and Rural Environment Governance. In: Proceedings of Heritage 2008. Barcelos: Green Lines Istituto, vol.2, pp.607-617.

De Masi A., 2018. Eco Sustainable Graphic Heritage Drawing for a Contemporary Territories Learning and the creating Smart Cities. In: Ioannides M. et al. (eds) Digital Heritage. Progress in Cultural Heritage: Documentation, Preservation, and Protection. EuroMed 2018. Lecture Notes in Computer Science, vol 11197, pp 262-270, Springer, Cham.

De Masi A., 2017, Protocollo Cognitivo e Comunicativo come Codice di Lettura per la Rappresentazione e Valorizzazione del Patrimonio Culturale dei Paesaggi Urbani Storici. In Proceeding $39^{\circ}$ Convegno Internazionale dei Docenti delle Discipline della Rappresentazione, Università degli Studi di Napoli, Gangemi Editore, Naples, pp.1043-1050.

Docci, M., 2009. Design and graphic analysis, Laterza.

Eilouti, B. H., 2018. Concept as the DNA for Morphogenesis: A Case Study of Contemporary Architecture in the Handbook of Research on Form and Morphogenesis in Modern Architectural Contexts, IGI Global.

Eilouti, B. H., 2018. Concept evolution in architectural design: an octonary framework, ScienceDirect. Volume 7, Issue 2, 180 196.

Ferrara, G., Campioni, G., 1997. Tutela della Naturalità Diffusa, Pianificazione degli Spazi Aperti e Crescita Metropolitana, Il verde Editoriale s.r.l., Milano.

Galli, F. B., 1777. Direzioni a' Giovani Studenti nel Disegno dell'Architettura Civile nell'Accademia Clementina, Bologna, L. della Volpe, tomo I.

Grosz, E. \& Eisenman, P., 2001. In-Between: The Natural in Architecture and Culture. In Architecture From The Outside: 
Essays On Virtual And Real Space. ed. Elizabeth Grosz, Peter Eisenman and E. A. Grosz, USA: MIT Press, 91-107.

Garagnani, S., 2013. Building Information Modeling and real world knowledge. A methodological approach to accurate semantic documentation for the built environment. In: Digital Heritage International Congress (DigitalHeritage).

Gur, S. O., 2008. What is creative? Creativity in architectural theory, practice and education (keynote speech). In DesignTrain Congress proceedings book - part I, 9-25, Amsterdam.

International Council on Monuments and Sites (ICOMOS), 2013. Charter for Places of Cultural Significance (The Burra Charter).

López, F.J., Lerones, P.M., Llamas, J., Gómez-GarcíaBermejo, J., Zalama E., 2017. A framework for using point cloud data of Heritage buildings towards geometry modeling in a BIM context: a case study on Santa Maria la Real de Mave Church. Int. J. Arch. Herit., 11, 965-986.

Mancini, F., Petrobelli, P., Pirrotta, N., Ferrero, M., V., Winter M.H., 1975. Illusione e Pratica Teatrale. Proposte per una lettura dello spazio scenico degli intermedi fiorentini all'Opera Comica Veneziana, Venezia: Neri Pozza Editore

Muzii R., 1997. I disegni di Ferdinando Sanfelice al Museo di Capodimonte, Electa Napoli.

Osello, A., Dalmasso, D., Del Giudice, M., Erba, D., Ugliotti, F.M., Patti, E., Davardoust, S., 2013. Information interoperability and interdisciplinarity: The BIM approach from SEEMPubS project to DIMMER project. Territ. Ital., 2, 9-22.

Serlio, S., Il Secondo libro di Perspettiva di Sebastiano Serlio. Parigi, J. Barbè.

United Nations Educational, Scientific and Cultural Organization (UNESCO), 2011. Recommendation on the Historic Urban Landscape.

Vignelli, M., 2012. Il Canone Vignelli, Postmedia Books. 